Article

\title{
Bleeding Characteristics and Improving Mechanism of Self-Flowing Tailings Filling Slurry with Low Concentration
}

\author{
Juanhong Liu *, Ruidong $\mathrm{Wu}$, Aixiang $\mathrm{Wu}$ and Shaoyong Wang \\ College of Civil and Resource Engineering, University of Science and Technology Beijing, Beijing 100083, China; \\ wrd0105@163.com (R.W.); aixiangwu1963@163.com (A.W.); wsyustb@126.com (S.W.) \\ * Correspondence: liujuanhong66@126.com; Tel.: +86-010-62333637
}

Received: 13 June 2017; Accepted: 20 July 2017; Published: 31 July 2017

\begin{abstract}
In order to solve the bleeding problem of self-flowing tailings filling slurry with low concentration, the influences of the dosage of special additive on the bleeding rate were investigated. The improving mechanism of special additive on the bleeding of tailings filling slurry was studied by measuring the bleeding rate and compressive strength of the slurry. Also, microstruture analysis was conducted by scanning electron microscopy (SEM), energy dispersive spectrometry (EDS), and infrared spectroscopy (IR) of the hardened body. The results show that with the slurry concentration of $60 \%$, the binder-to-tailings ratio of $1: 6$ and the special additive dosage of $10 \%$, the filling slurry is not bleeding and the compressive strength of hardened body can increase by $43.5 \%$ at three days. A large amount of needle-like ettringite is generated in the hardened body after adding the special additive, and the structure becomes denser. The special additive can effectively improve the bleeding of the filling slurry and increase the compressive strength of the filling material at early age.
\end{abstract}

Keywords: self-flowing; tailings filling; bleeding rate; early strength; improve

\section{Introduction}

Most large mines have progressed into deep exploitation in China. With the increasing of mining depth, the tailings filling mining method is more widely used. The transport length of filling slurry is great, which leads to high pumping costs. In order to transport better, a decrease of the filling solids concentration is needed. However, the decreasing of slurry concentration means a higher seepage water bleeding rate, which causes many engineering problems. Thus, a new kind of material should be developed. This material can satisfy low solids concentration in the conveying process and reduce the bleed rate of seepage water after entering the stope as well as increase the strength. The use of tailings for cemented filling can efficiently utilize all mine tailings, and reduce environmental pollution and cost of filling the mine [1]. The tailings are not required to be graded, so the filling will have good conveying performance and high filling efficiency [2,3]. However, at low solids concentration high bleed water seepage rate will occur when the self-flowing tailings filling slurry is deposited underground [4]. The bleeding directly causes the shrinkage of filling resulting in a decreased capacity to fill to the roof and therefore affecting the stope safety. Moreover, the seepage also causes the pollution of underground roadway and increases the cost of water drainage. In order to solve these problems, a special additive was developed. Adding the special additive to the filling slurry would have good performance on bleeding and improve compressive strength even though its solids concentration is at a low level.

The rheological properties and strength characteristics of cemented tailings filling slurry have been widely studied in the last decade [5-8], but there is little research on reducing bleeding water seepage and its mechanism. This paper focuses on the bleeding problems of self-flowing tailings filling 
slurry with low solids concentration. The influence of dosage of a special additive on the seepage water bleed rate was investigated deeply. The improvement was studied by measuring the bleeding rate and unconfined compressive strength (UCS) of filling and analyzing the scanning electron microscopy (SEM), energy dispersive spectrometry (EDS), and infrared spectroscopy (IR) of the hardened body. Finally, a suitable combination of slurry concentration, binder-to-tailings ratio and special additive dosage were confirmed, under which the filling slurry is not bleeding and the compressive strength of hardened body can increase.

\section{Materials and Methods}

\subsection{Raw Materials}

P.O 42.5 Ordinary Portland Cement (Table 1 shows the main properties of cement) and tailings from a certain mining enterprise were used in this study. Binder powder and high solidified water additive were used as cementing materials and special additive, respectively. The particle size distribution of tailings is shown in Figure 1.

Table 1. Main properties of cement.

\begin{tabular}{|c|c|c|c|c|c|c|c|c|}
\hline \multirow{2}{*}{$\begin{array}{c}\text { Water Requirement } \\
\text { for Normal } \\
\text { Consistency/\% }\end{array}$} & \multirow{2}{*}{$\begin{array}{c}\text { Initial } \\
\text { Setting } \\
\text { Time/min }\end{array}$} & \multirow{2}{*}{$\begin{array}{c}\text { Final } \\
\text { Setting } \\
\text { Time/min }\end{array}$} & \multirow{2}{*}{$\begin{array}{c}\text { Specific } \\
\text { Surface } \\
\text { Area } / \mathrm{m}^{2} \cdot \mathrm{kg}^{-1}\end{array}$} & \multirow{2}{*}{ Soundness } & \multicolumn{2}{|c|}{$\begin{array}{c}\text { Bending } \\
\text { Strength/MPa }\end{array}$} & \multicolumn{2}{|c|}{$\begin{array}{l}\text { Compressive } \\
\text { Strength/MPa }\end{array}$} \\
\hline & & & & & 3 day & 28 day & 3 day & 28 day \\
\hline 29.2 & 162 & 226 & 392 & Qualified & 4.9 & 9.9 & 27.5 & 50.0 \\
\hline
\end{tabular}

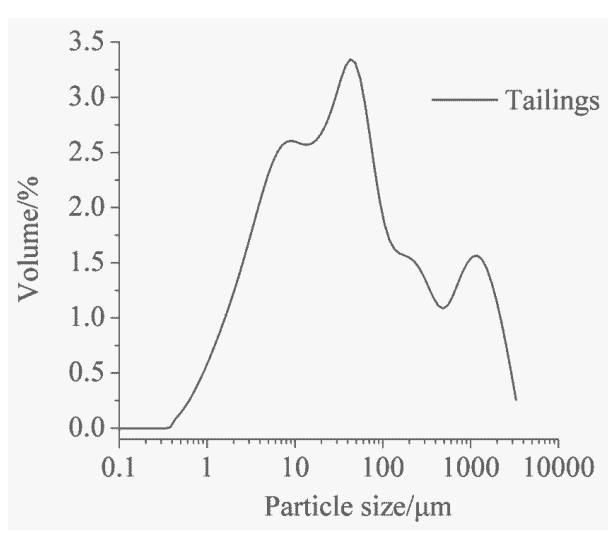

Figure 1. Particle size distribution of tailings.

\subsection{Test Methods}

Seepage Water Bleed Rate:

The slurry was weighed after preparation $\left(\mathrm{as}_{1}\right)$, then it was placed stationarily. At the time of $0.5,1,2$, and $8 \mathrm{~h}$, the seepage water was sucked out rapidly with a straw, and the rest of slurry was weighed $\left(\right.$ as $\left.\mathrm{m}_{2}\right)$. The seepage water bleed rate, $\alpha$, was calculated according to Equation (1)

$$
\alpha=\left(m_{1}-m_{2}\right) / m_{0}
$$

where $m_{0}$ is the weight of water used for the preparation of tailings filling slurry.

Unconfined Compressive Strength:

The slurries were cast into molds with dimensions of $70.7 \times 70.7 \times 70.7 \mathrm{~mm}^{3}$. The hardened filling material was stripped from molds after cured for two days. Then all the filling samples were 
placed in a standard curing box $\left(20^{\circ} \mathrm{C}, 95 \%\right.$ relative humidity). The unconfined compressive strength of samples was measured by WHY-600 (Hualong, Shanghai, China) uniaxial press machine.

Microstructure Analysis:

The filling specimens were sampled at the age of $0.5 \mathrm{~h}, 2 \mathrm{~h}$, and 1 day. Then the samples were dried to stop hydration at $30{ }^{\circ} \mathrm{C}$ for $0.5 \mathrm{~h}$. The morphology of the samples were observed by SEM (FEI Quanta, Hillsboro, OR, USA) and the elemental analysis was done by EDS (FEI Quanta, Hillsboro, OR, USA). The IR was analyzed by NEXUS670 (Thermo Nicolet Corporation, Hillsboro, OR, USA) instrument using $\mathrm{KBr}$ compression method. The scanning range was 4000 to $400 \mathrm{~cm}^{-1}$.

\section{Results and Discussions}

Considering of economic problems, the binder-to-tailings ratio is chosen as 1:6 (mass ratio). According to the in situ application of tailing filling in China, the solids concentration of self-flowing slurry is confirmed at $55 \%-65 \%$. Here, the solids concentration used for bleeding rate research were $57 \%, 60 \%, 63 \%$, and $66 \%$.

\subsection{Effect of Solids Concentration on Slurry Bleeding Rate}

High bleeding water losses are verified for low solids concentration slurry. Due to the loss of water, the hardened filling will shrink and the quality of the filling is difficult to guarantee. Figure 2 shows the bleeding rate change tendency of tailings filling slurry with different solids concentration.

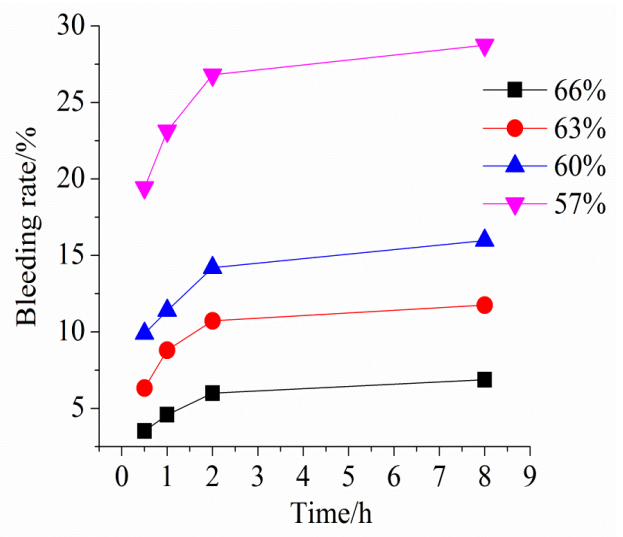

Figure 2. Effect of solids concentration on the bleeding rate of slurry.

It can be seen from Figure 2 that the bleeding rate is increasing steadily with time, but its increment is decreasing. It reaches a steady state after $8-10 \mathrm{~h}$. Since the bleeding water cannot return to the slurry, it results in the shrinkage of the slurry, which explains why the stope roofs cannot be tightly filled. With a decrease of slurry solids concentration, the bleeding rate increases. When the slurry concentration is reduced from $60 \%$ to $57 \%$, the bleeding rate significantly increases from $15.98 \%$ to $28.75 \%$. Therefore, in order to keep the slurry self-flowing in the pipe and avoid bleeding, the slurry concentration should not be too low.

\subsection{Effect of Special Additive on Bleeding Rate and Slurry Strength}

In order to maintain self-flowing and avoid bleeding in the conveying pipe, a special high solidified water additive is developed. The dosage of special additive was determined by the percentage of binder powder. Figure 3 shows the influence of special additive content on bleeding rate for a slurry sample at $8 \mathrm{~h}$. Taking test results of bleeding rate and economy factors into account, the slurry solids concentration is $60 \%$. 


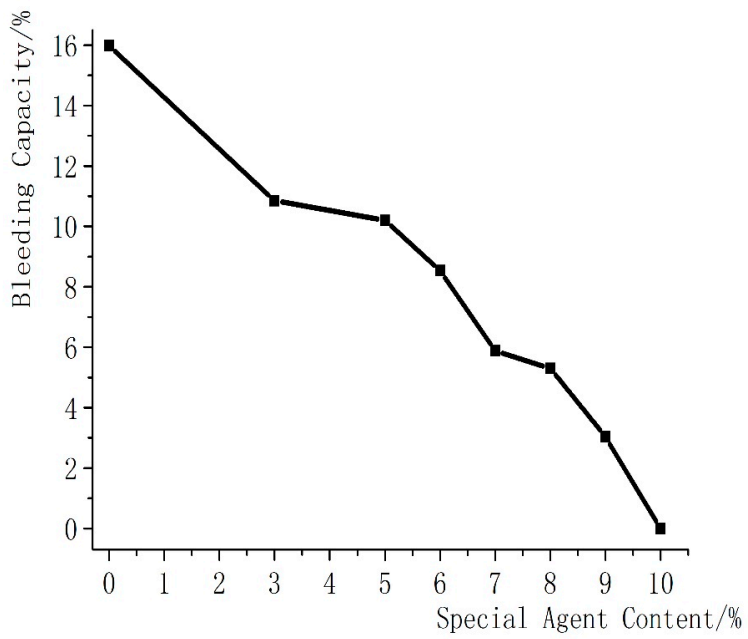

Figure 3. Effect of special additive on bleeding rate of slurry at $8 \mathrm{~h}$.

From Figure 3, it is clear that as the dosage of high solidified water additive increases, the $8 \mathrm{~h}$ bleeding water loss decreases. When the dosage of special additive accounts for $10 \%$ of the binder powder, the bleeding water (15.98\% as shown in Figure 2) which would evaporate in the first $30 \mathrm{~min}$, was retained in the filling under the hardened stage.

Figure 4 illustrates the unconfined compressive strength of filling slurry with a binder-to-tailings ratio of $1: 6$ and a solids concentration of $60 \%$ at the age of 3, 7, and 28 days. It can be perceived that when the dosage of special additive is $10 \%$, the UCS of filling samples will increase by $43.5 \%, 41.8 \%$, and $15.1 \%$ at 3,7 , and 28 days, respectively, compared with non-additive samples.

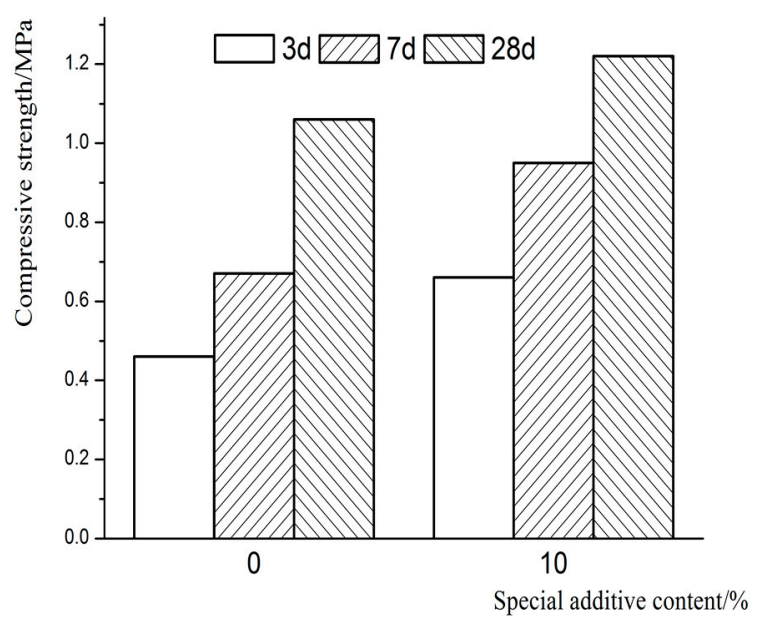

Figure 4. Effect of special additive on compressive strength.

\subsection{Effect of Special Additive on Microstructure of Hardened Filling Slurry}

Figure 5 exhibits the SEM micrographs of the slurry samples without special additive at $60 \%$ solids concentration and 1:6 binder-tailings ratio after $30 \mathrm{~min}, 2 \mathrm{~h}$, and 1 day.

As seen in Figure $5 a, b$, there is few gel at 0.5 and $2 \mathrm{~h}$. The distance between particles is large. It is indicated that there is a large amount of free water in the slurry. A small number of bulk crystals and gels exist in the slurry at 1 day, as shown in Figure $5 c$. Due to the consolidation of slurry and the loss of bleeding water, the density of the slurry increases. However, owing to a few hydration products, the cemented performance is poor and the hardened slurry has almost no strength. 


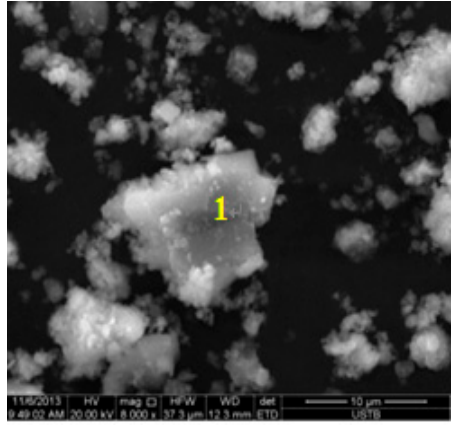

(a)

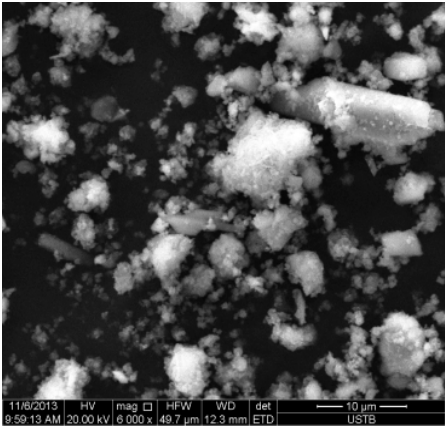

(b)

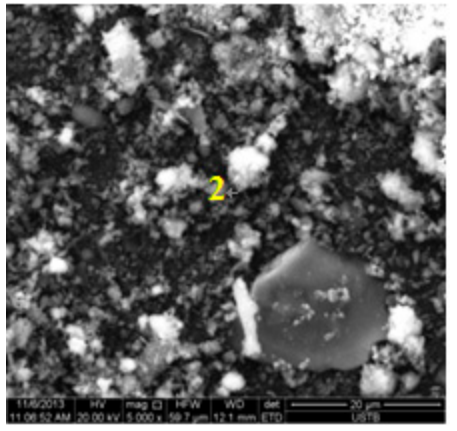

(c)

Figure 5. SEM micrographs of filling slurry without special additive at different hydration ages: (a) $30 \mathrm{~min}$; (b) $2 \mathrm{~h}$; (c) 1 day.

The energy spectrums of slurry from Figure $5 a$ " 1 " and Figure $5 c$ " 2 " are given in Figure 6. From Figure $6 \mathrm{a}$, it is found that there are no hydration products generating on the particle surface after $30 \mathrm{~min}$. It is mainly silica, alumina, calcium oxide, and other components of tailings. The four basic elements of ettringite $(\mathrm{O}, \mathrm{Al}, \mathrm{S}$ and $\mathrm{Ca})$ are presented in Figure $6 \mathrm{~b}$. It is also revealed that there is a small amount of needle-like ettringite in slurry after $1 \mathrm{~d}$ hydration.

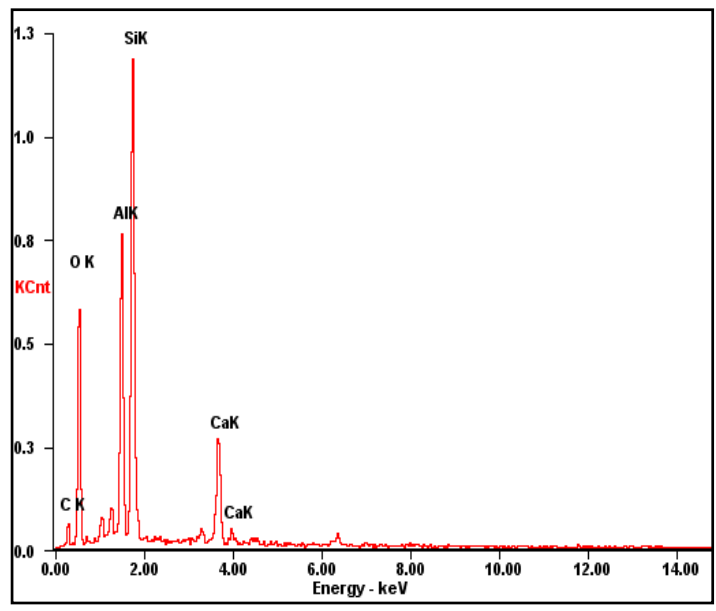

(a)

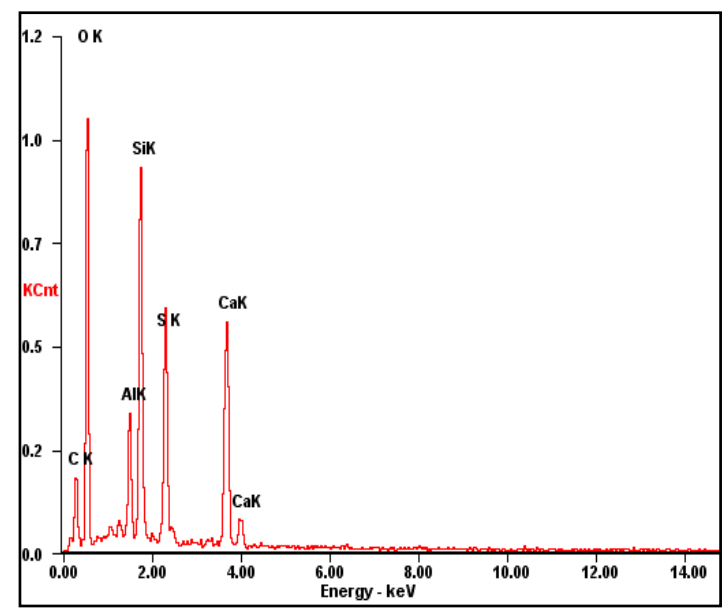

(b)

Figure 6. Energy spectrums of slurry from Figure 5a "1" (a) and Figure 5c "2" (b); (a) EDS from Figure 5a; (b) EDS from Figure 5c.

Figure 7 shows the SEM photographs of filling slurry with special additive at $0.5 \mathrm{~h}, 2 \mathrm{~h}$, and 1 day at a solids concentration of $60 \%$ and a binder-to-tailings ratio of 1:6.

A small number of hydration products are observed in the hardened filling slurry at $30 \mathrm{~min}$ (Figure 7a). Although some ettringite crystals and gels are generated, these crystals are relatively short and are not intertwined together, and most of them still disperse. The particles are relatively close, indicating nearly no free water exists. There is relatively more gels in the hardened filling slurry at $2 \mathrm{~h}$ (Figure $7 \mathrm{~b}$ ). Furthermore, needle-like ettringite crystals and hexagonal plate calcium hydroxide crystals exist. The crystals and gels agglomerate together. At the age of 1 day, ettringite crystals and gels intertwine with each other, forming a much more dense internal structure (Figure 7c). 


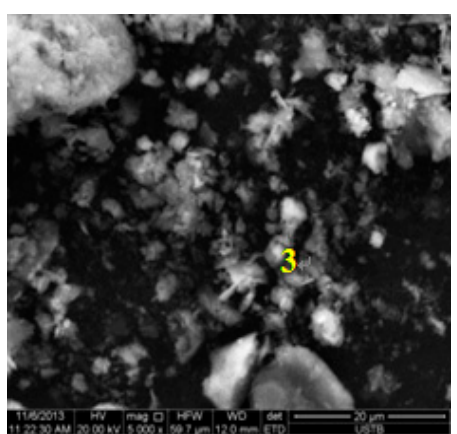

(a)

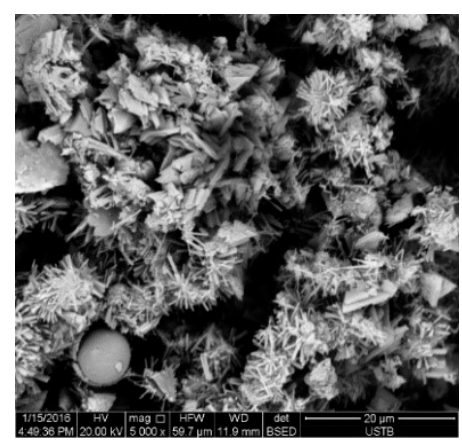

(b)

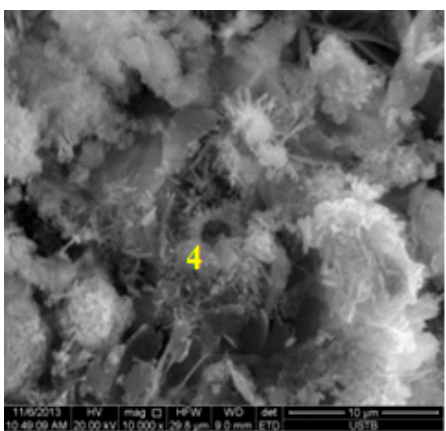

(c)

Figure 7. SEM photographs of filling slurry with special additive at different hydration ages: (a) $30 \mathrm{~min}$; (b) 2 h; (c) 1 day.

The energy spectrums of slurry from Figure $7 \mathrm{a}$ " 3 " and Figure $7 \mathrm{c}$ " 4 " are given in Figure 8. It can be seen that the four essential elements- $\mathrm{Ca}, \mathrm{Al}, \mathrm{S}$, and $\mathrm{O}-\mathrm{of}$ ettringite exist in hardened filling slurry at $30 \mathrm{~min}$. It proves that the needle-like crystals in Figure $7 \mathrm{a}$ are ettringite. The formation of ettringite greatly reduces the occurrence of slurry bleeding. The peak values of $\mathrm{Al}, \mathrm{S}$, and $\mathrm{Ca}$ increase at 1 day (Figure $8 b$ ). It is elucidated that the number of hydration products increases significantly after hydrating for 1 day.

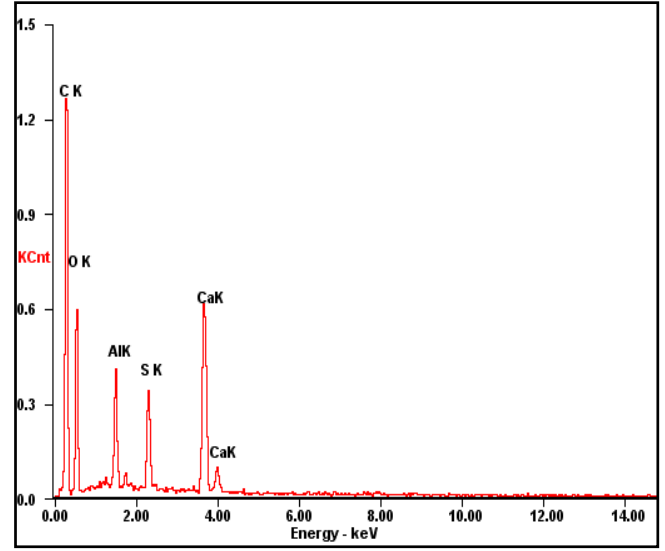

(a)

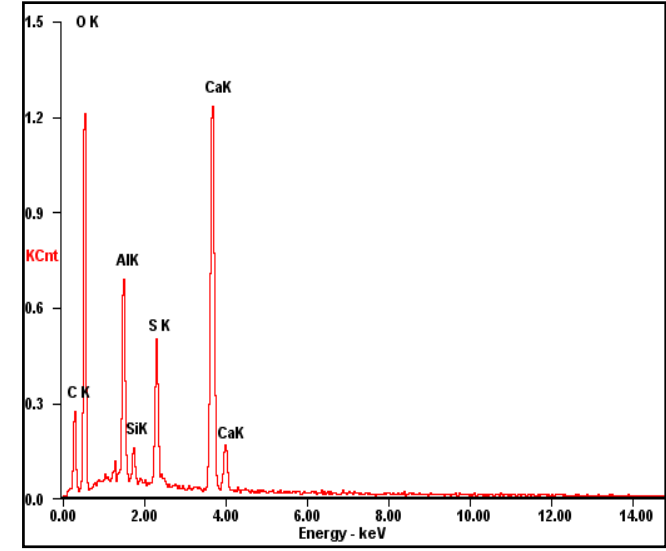

(b)

Figure 8. Energy spectrums of slurry from Figure 7a " 3 " (a) and Figure 7c " 4 " (b); (a) EDS from Figure 7a; (b) EDS from Figure 7c.

\subsection{Analysis of Infrared Spectrum Characteristics of Hardened Filling Slurry}

The composition and content of hydration products formed during the hydration process of cement-based materials can be qualitatively and quantitatively analyzed by infrared spectroscopy. The quantitative analysis of infrared spectrum is mainly based on the measurement of absorbance. The concentration of the sample is proportional to the absorbance.

The molecular structure of ettringite is $\mathrm{Ca}_{6}\left[\mathrm{Al} \cdot(\mathrm{OH})_{6}\right]_{2}\left(\mathrm{SO}_{4}\right)_{3} \cdot 26 \mathrm{H}_{2} \mathrm{O}$, which contains a large amount of water molecules. The 26 water molecules are combined in the form of $\mathrm{H}_{2} \mathrm{O}$ and the water existing in the form of $\mathrm{OH}$ is equivalent to only six water molecules. In the infrared spectrum, the absorption peak of $3640 \mathrm{~cm}^{-1}$ reflecting that the $[\mathrm{OH}]$ stretching vibration is not obvious. While the absorption peak of $\mathrm{H}_{2} \mathrm{O}$ stretching vibration (about 1650 and $3460 \mathrm{~cm}^{-1}$ ) is strong. The strong absorption band around $1120 \mathrm{~cm}^{-1}$ belongs to the asymmetric stretching vibration of $\left[\mathrm{SO}_{4}\right]$, and the flexural vibration of $\left[\mathrm{SO}_{4}\right]$ is $610 \mathrm{~cm}^{-1}$. The formation rate of ettringite in the hardened filling slurry 
can be determined according to the change of $3640 \mathrm{~cm}^{-1}[\mathrm{OH}]$ absorption band and the $1122 \mathrm{~cm}^{-1}$ $\left[\mathrm{SO}_{4}\right]$ absorption band in the infrared spectrum [9]. Figure 9 shows that after the incorporation of special additive, there is a shoulder at $3640 \mathrm{~cm}^{-1}$ in the infrared spectrum of hardened filling slurry at 1 day, indicating that the ettringite is formed. In contrast, no absorption band or shoulder appears at $3640 \mathrm{~cm}^{-1}$ in the infrared spectrum of hardened filling slurry without special additive at 1 day.

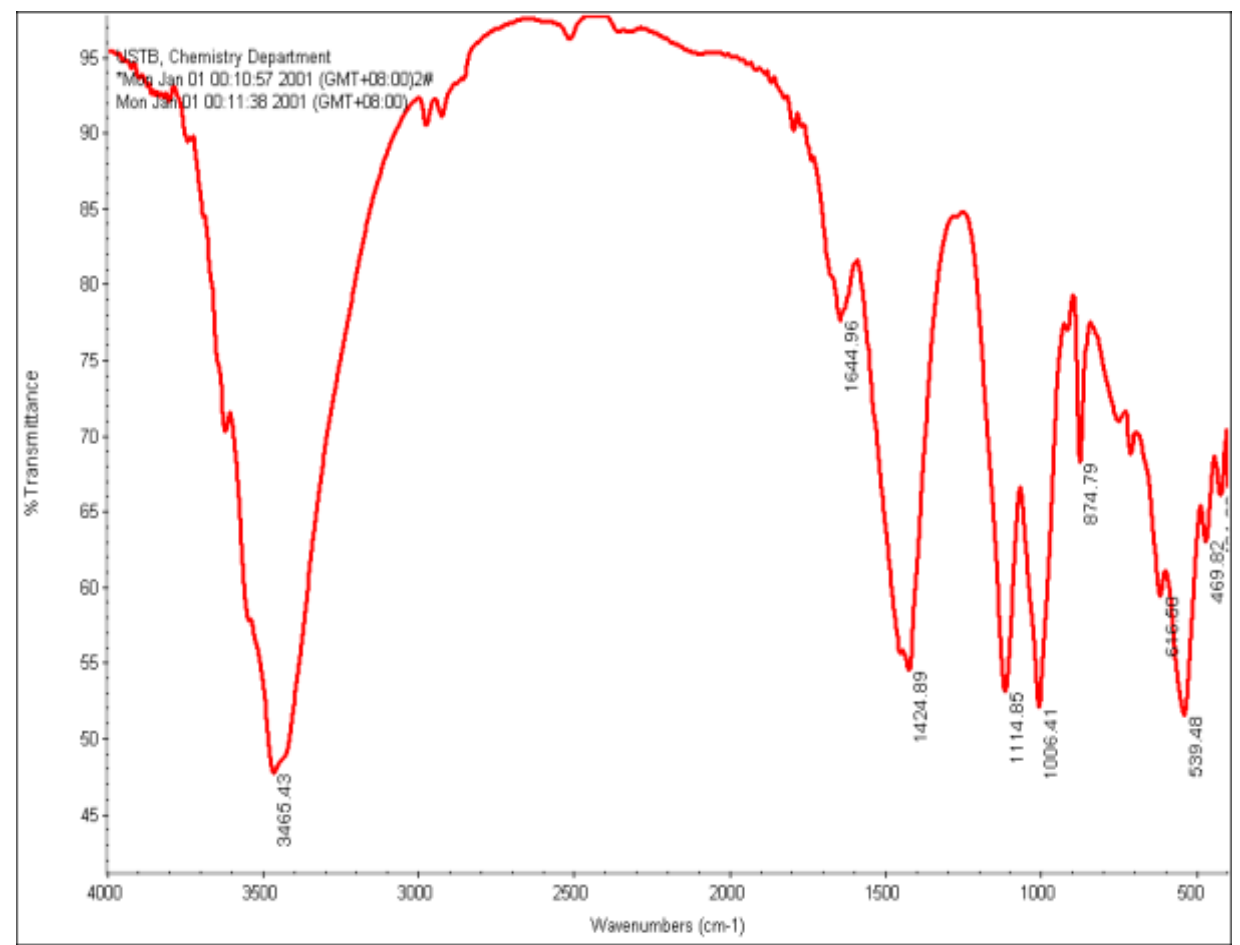

(a)

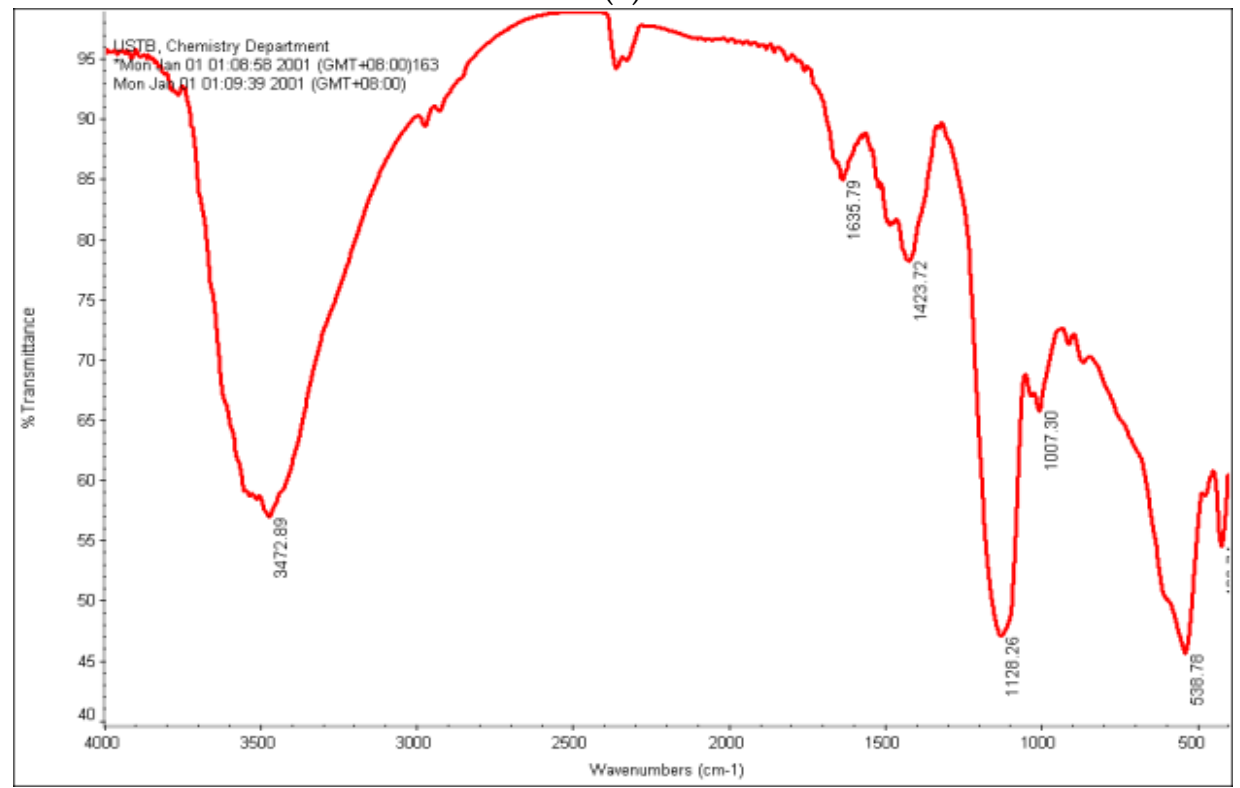

(b)

Figure 9. IR spectra of 1 day hardened filling slurry: (a) With special additive; (b) Without special additive.

The C-S-H gel is caused by $\left[\mathrm{SiO}_{4}\right]$ asymmetric stretching vibration of the absorption band located at 970,658 , and $453 \mathrm{~cm}^{-1}$, which is the symbol for identifying C-S-H. It can be seen from Figure 8 a that the absorption band of $\left[\mathrm{SiO}_{4}\right]$ at 970 and $453 \mathrm{~cm}^{-1}$ changes with hydration process, moving to a high 
wave number. These peaks are more obvious after hydrating for 1 day, indicating that after adding high solidified water additive, there is a certain amount of $\mathrm{C}-\mathrm{S}-\mathrm{H}$ gel in the filling after hydrating for 1 day. However, the absorption peak of $\mathrm{C}-\mathrm{S}-\mathrm{H}$ gel is not found in the infrared spectrum of the hardened filling slurry without special additive after hydrating for 1 day.

Through the analysis above, the bleeding rate decreases with the increasing of solids concentration, so the slurry solids concentration should not be too low. The special additive is quite practical in engineering. With moderate special additive, the slurry demonstrates good performance both on bleeding rate and compressive strength. How to enhance the strength at a higher level can be studied in further research. Also, a specific application is needed to verify the test results in the future.

\section{Conclusions}

This paper studied variation trend of the bleeding rate with the solids concentration. The improving mechanism of special additive was studied by measuring the bleeding rate and compressive strength of the slurry. Also, microstruture analysis was conducted by SEM, EDS, and IR of the hardened body. The main conclusions are as follows:

(1) In order to keep the filling slurry self-flowing in the pipe, the slurry solids concentration should not be too low. When the slurry solids concentration is reduced from $60 \%$ to $57 \%$, the bleeding rate significantly increases from $15.98 \%$ to $28.75 \%$.

(2) When the slurry solids concentration is $60 \%$, the binder-to-tailings ratio is $1: 6$, and the dosage of special additive accounts for $10 \%$ of the binder powder, the filling slurry does not have any bleed water loss and the compressive strength of hardened filling slurry increases by $43.5 \%$ after three days. A suitable combination was put forward for actual engineering.

(3) On a micro level, a large amount of needle-like ettringite is generated in the hardened slurry after adding the special additive, and the structure becomes denser.

Acknowledgments: This research was financially supported by the National Natural Science Foundation of China (No. 51374036).

Author Contributions: Juanhong Liu and Aixiang Wu conceived and designed the experiments; Ruidong Wu performed the experiments; Shaoyong Wang contributed materials; Juanhong Liu and Ruidong Wu wrote the paper. All authors read and approved the manuscript.

Conflicts of Interest: The authors declare no conflict of interest.

\section{References}

1. Zhai, Y.G.; Wu, A.X.; Wang, H.J.; Chen, Q.R.; Xiao, Y.T.; Shou, Z.Y. Threshold mass fraction of unclassified-tailings paste for backfill mining. J. Univ. Sci. Technol. Beijing 2011, 33, 795-799. (In Chinese)

2. Zhang, T.; Ma, M.; Wang, H.; Xu, H. A nonlinear rheological model of backfill material for retaining roadways and the analysis of its stability. Min. Sci. Technol. (China) 2011, 21, 543-546. (In Chinese) [CrossRef]

3. Fusi, L.; Farina, A.; Rosso, F. Flow of a Bingham-like fluid in a finite channel of varying width: A two-scale approach. J. Non-Newton. Fluid Mech. 2012, 177, 76-88. [CrossRef]

4. Wang, Y.; Wang, H.J.; Wu, A.X. Research of fine tailings bleeding characteristics and influence factors. Gold 2011, 32, 51-54. (In Chinese)

5. Wu, D.; Cai, S.J.; Yang, W.; Wang, W.X.; Wang, Z. Simulation and experiment of backfilling pipeline transportation of solid-liquid two-phase flow based on CFD. Chin. J. Nonferrrous Met. 2012, 22, 2133-2140. (In Chinese)

6. Syrakos, A.; Georgiou, G.C.; Alexandrou, A.N. Solution of the square lid-driven cavity flow of a Bingham plastic using the finite volume method. J. Non-Newton. Fluid Mech. 2013, 195, 19-31. [CrossRef]

7. Peyronnard, O.; Benzaazoua, M. Alternative by-product based binders for cemented mine backfill: Recipes optimisation using Taguchi method. Miner. Eng. 2012, 29, 28-38. [CrossRef] 
8. Fall, M.; Adrien, D.; Celestin, J.C.; Pokharel, M.; Toure, M. Saturated hydraulic conductivity of cemented paste backfill. Miner. Eng. 2009, 22, 1307-1317. [CrossRef]

9. Li, D.D. Infrared Spectroscopic Study of Sulphoaluminate Cement. J. Chin. Ceram. Soc. 1984, 12, 119-125. (In Chinese) 